\title{
The effect of nurses training on ventilator-associated pneumonia (VAP) prevention bundle on VAP incidence rate at a critical care unit
}

\author{
Rashad Ismail *, Eman Zahran \\ School of Nursing, Beirut Arab University, Beirut, Lebanon
}

Received: April 22, 2015

DOI: $10.5430 /$ jnep.v5n $12 \mathrm{p} 42$
Accepted: August 13, $2015 \quad$ Online Published: September 14, 2015

URL: http://dx.doi.org/10.5430/jnep.v5n12p42

\begin{abstract}
Most of critically ill patients need mechanical ventilator (MV) which assists or replaces spontaneous breathing. Mechanically ventilated patients are more likely to develop pulmonary infection and ventilated associated pneumonia (VAP). Intubation bypasses the normal airway protective mechanisms and acts as a direct route for bacterial invasion to the airway. VAP has been associated with increased morbidity, longer hospital stay, increased health care costs, and higher mortality rates. Critical care nurse has an important and crucial role in preventing VAP. Evidence indicates that training of critical care nurses about the implementation of VAP Prevention Bundle had a great effect on decreasing the incidence of VAP. Therefore, this study was conducted to determine the effect of nurses training on VAP Prevention Bundle on VAP incidence Rate at a Critical Care Unit.
\end{abstract}

Key Words: Critical care unit, Ventilator, Infection, Ventilated associated pneumonia, Ventilated associated pneumonia bundle, Critical care nurses

\section{INTRODUCTION}

Critically ill patients are characterized by the presence of actual or potential life threatening problems. Most of these patients are dependent on health care providers and technological assistance. Among technological assistance devices in critical care units (CCUs) is the mechanical ventilator (MV) which assists or replaces spontaneous breathing and requires tracheal intubation. ${ }^{[1]}$

Mechanically ventilated patients are more likely to develop pulmonary infection and pneumonia. Intubation required for MV hinders patient's ability to take oral feeding resulting in shifting bacterial strains naturally present in the mouth from being normal flora to pathogenic strains. Intubation bypasses also the normal airway protective mechanisms and acts as a direct route for bacterial invasion to the airway. ${ }^{[2,3]}$ More- over, critically ill patients have immunological deficiencies because of their illnesses, making them unable to respond to bacterial invasion of the lungs.

According to the Center for Disease Control and Prevention (CDC, 2012), Ventilator associated pneumonia (VAP) is that type of pneumonia developing 48 hours post intubation. It is diagnosed by the presence of a number of indicators including; manifestations of pulmonary infection as; presence of a disturbance in body temperature $>38^{\circ} \mathrm{C}$ or $<36^{\circ} \mathrm{C}$, leukocytosis and purulent tracheal secretions, new or persistent infiltrates detectable on chest radiographs, and positive deep tracheal aspiration culture. ${ }^{[4]}$

VAP is the most commonly reported health care acquired infection in CCUs. The VAP rates might count $27 \%$ of all infections in CCUs. ${ }^{[2,3]}$ The National Healthcare Safety Net-

*Correspondence: Rashad Ismail; Email: rashad_icu@yahoo.com; Address: School of Nursing, Beirut Arab University, Beirut, Lebanon. 
work reported in 2007, 2.1 to 10 incidents per 1,000 ventilator days in New York. Research evidence (2003) shows that VAP incidence reaches around $32 \%$ in Athens. ${ }^{[5]}$ VAP increases the severity of illness as it elevates oxygen demands, sputum production, produces alveolar collapse leading to impaired gas exchange. The patient might experience discomfort, agitation, delirium, immobility, and/or risk for impaired skin integrity, hemodynamic instability, as well as an increased stress response and malnutrition. ${ }^{[6]}$

Because VAP has been associated with increased morbidity, longer hospital stay, increased health care costs, and higher mortality rates so its prevention would be major challenge in CCUs. Recently, reducing the risk of VAP had been identified as a national patient safety goal. Therefore, evidence based guidelines were created in 2004 which is finally updated in 2011 by the Institute for Healthcare Improvement (IHI) in an attempt to find a solution to the problem of VAP. These guide lines are called VAP Prevention Bundle and they incorporate a number of evidence based strategies proved to prevent VAP. ${ }^{[7,8]}$

The role of the critical care nurse in preventing VAP is crucial. Most of the measures included in VAP Prevention Bundle guidelines are largely related to the daily nursing care activities. The key concepts of the VAP Prevention Bundle are five concepts. These concepts include; head of bed (HOB) elevation 30 degrees or more, use of thrombo-embolic prophylaxis, use of peptic ulcer disease prophylaxis, daily interruption of sedative drug infusions with a constant assessment of readiness to extubate, and providing oral care. ${ }^{[9]}$

\section{Methods Of STUdy}

The study tools were developed by the researcher after reviewing the related literature. ${ }^{[5,6]}$

Two groups of patients were sequentially enrolled in the study: control and experiential study groups. The control group included Mechanical Ventilated patients admitted to the critical care unit (CCU) before conducting the training program, while the experimental group included those Mechanical Ventilated patients admitted to the CCU after the training.

For patients in both groups

- A tool was used to collect patient related data including: age, sex, past medical/surgical history, duration of intubation/hospitalization, past and current medication.

- Before the training (for the control group) or after the training (for the experimental group) and over a period of three months, respiratory assessment to each patient was done every morning, with special atten- tion to signs of respiratory infection. This assessment was done regularly until patient's extubation, death, or transfer to another hospital.

- When manifestations of respiratory infection were detected, sputum culture and chest X-ray were done in order to confirm the diagnosis of VAP.

For the critical care nurses included in the study:

\section{Before the training:}

- All critical care nurses were assessed for their knowledge about VAP diagnosis, manifestations, risk factors and VAP Prevention Bundle.

- Nurses were observed individually for VAP Prevention Bundle related practices. Observations were carried to each nurse twice at two different mornings.

The training session: A training session was conducted followed by a demonstration to VAP prevention bundle practices.

\section{After the training:}

- Reassessment of nurses' knowledge and practices regarding VAP and VAP prevention bundle was done with the same methodology of pre-assessment, and over the same duration of time.

- The effect of VAP prevention bundle training on nurses' knowledge, and practices, and on the incidence of VAP over three months before the training was compared to that after the training.

\section{Results}

As shown Table 1, the age nurses varied from 23 years to 45 years with an average of $27.67 \pm 5.94$ years. They were equally distributed by sex. The majority of participants (91.67\%) were holding BS Nursing degree and were working as registered nurses.

Table 2 represents a comparison between the general VAP related knowledge before the training compared to that after the training Results showed that there were improvements in most items of nurses' general knowledge related to VAP after the training which were statistically significant.

Table 3 compares the knowledge related to the VAP prevention bundle of nurses before and after training. With respect to head elevation, nurses knowledge had been improved from $79.2 \%$ to $100 \%$ afterward. The improvements in thrombo-embolic and peptic ulcer prophylaxis were statistically significant. Regarding nurses' knowledge about Daily Sedation Vacation and Daily Assessment of the Readiness to Wean, knowledge improved from $62.5 \%$ to $70.85 \%$ which 
was statistically insignificant. Concerning Mouth Care with Chlorhexidine, the improvement was statistically insignificant.

Table 1. General characteristics of the studied nurses

\begin{tabular}{|c|c|c|}
\hline Variables & N (12) & \\
\hline \multirow{3}{*}{ Age/years } & Min-Max & Mean \pm SD \\
\hline & $23-45$ & $27.6 \pm 5.94$ \\
\hline & N (12) & $\%$ \\
\hline \multicolumn{3}{|l|}{ Sex } \\
\hline Male & 6 & 50 \\
\hline Female & 6 & 50 \\
\hline \multicolumn{3}{|l|}{ Educational Level } \\
\hline Nursing Institutes (TS) & 1 & 8.33 \\
\hline Bachelor of Nursing Science & 11 & 91.67 \\
\hline \multicolumn{3}{|l|}{ Position } \\
\hline Technical Nurse & 1 & 8.33 \\
\hline Registered Nurse & 11 & 91.67 \\
\hline \multicolumn{3}{|l|}{ Years of experience in ICU } \\
\hline $1-5$ years & 9 & 75 \\
\hline $6-10$ years & 2 & 16.67 \\
\hline More than 10 years & 1 & 8.33 \\
\hline Min-Max & \multicolumn{2}{|l|}{ 2-12 years } \\
\hline Mean $\pm \mathrm{SD}$ & \multicolumn{2}{|c|}{$5.17 \pm 2.86$ years } \\
\hline
\end{tabular}

Table 4 shows that with respect to the head elevation of 30-45 degrees, it was that $25 \%$ of nurses only were compliant to this practice before the training compared to $91.7 \%$ of nurses after training $(p=.000)$. Moreover, the compliance of nurses to the practices; DVT and PUD prophylaxis, daily sedation vacation, and daily assessment of the readiness to wean significantly increased after training; from $72.74 \%, 79.54 \%$, $12.89 \%, 22.25 \%$, and $3.54 \%$ to $100 \%$ in these practices; respectively.

Table 5 shows that, regarding the distribution of the studied patients' groups according to sex, it was found that the male sex in both groups was the predominate which constitutes $53.33 \%$ and $71.43 \%$ of the group of studied patients before the training and after, respectively; with no statistical significant difference between both groups $(p=.235)$. Concerning the length of intubation and mechanical ventilation, there was no statistical significant difference between patients' group existed before the training and those existed after the training ( $p=.392, .556$, respectively).

Table 2. Comparison between nurse's general VAP related knowledge before and after the training

\begin{tabular}{|c|c|c|c|c|c|}
\hline \multirow{2}{*}{ Knowledge } & \multicolumn{2}{|c|}{ Before the training $(n=12)$} & \multicolumn{2}{|c|}{ After the training $(n=12)$} & \multirow{2}{*}{$p$-value } \\
\hline & Correct (\%) & Incorrect (\%) & Correct (\%) & Incorrect (\%) & \\
\hline Definition of VAP & 41.7 & 58.3 & 100 & 0 & $.007^{*}$ \\
\hline Diagnosis of VAP: & 27.8 & 72.2 & 86.1 & 13.9 & $.007 *$ \\
\hline Criteria of VAP & 41.7 & 58.3 & 91.7 & 8.3 & $.033^{*}$ \\
\hline Indicators of diagnosing VAP & 25 & 75 & 75 & 25 & $.047 *$ \\
\hline Positive sputum & 16.7 & 83.3 & 91.7 & 8.3 & .537 \\
\hline Complications of mechanical ventilation & 33.3 & 66.7 & 66.7 & 33.3 & .231 \\
\hline Patient's related risk factors: & 52.8 & 47.2 & 97.2 & 2.8 & $.006^{*}$ \\
\hline Disturbed level of consciousness & 66.7 & 33.3 & 100 & 0 & .091 \\
\hline Malnutrition & 16.7 & 83.3 & 100 & 0 & .140 \\
\hline Aspiration of contaminated secretion & 75 & 25 & 91.7 & 8.3 & .122 \\
\hline Nurses' practices related risk factors: & 50.0 & 50.0 & 100 & 0 & $.005^{*}$ \\
\hline Suctioning, frequently & 66.7 & 33.3 & 100 & 0 & $.028 *$ \\
\hline Utilizing clean gloves for tracheal suction & 50 & 50 & 100 & 0 & $.005 *$ \\
\hline Performing ineffective hand hygiene & 58.35 & 41.65 & 100 & 0 & $.012 *$ \\
\hline Rubbing with Alcohol when visible secretions & 0 & 100 & 100 & 0 & / \\
\hline Washing hands when there is no visible secretions & 75 & 25 & 100 & 0 & .064 \\
\hline Doctors' practices related risk factors & 30.6 & 69.4 & 94.5 & 5.5 & $.005^{*}$ \\
\hline Giving multiple antibiotics & 25 & 75 & 91.7 & 8.3 & $.001^{*}$ \\
\hline Giving broad spectrum antibiotics & 50 & 50 & 91.7 & 8.3 & $.025 *$ \\
\hline Intubating patients, nasally & 16.7 & 83.3 & 100 & 0 & .140 \\
\hline
\end{tabular}

${ }^{*} p$ is significant if $\leqslant .05$ 
Table 3. Comparison between nurse's VAP Prevention Bundle related knowledge before and after the training

\begin{tabular}{|c|c|c|c|c|c|}
\hline \multirow{2}{*}{ Knowledge Item } & \multicolumn{2}{|l|}{ Pre $(n=12)$} & \multicolumn{2}{|l|}{ Post $(n=12)$} & \multirow{2}{*}{$P$-value } \\
\hline & Correct (\%) & Incorrect (\%) & Correct (\%) & Incorrect (\%) & \\
\hline Elevating Head of bed 30-45 degrees & 79.2 & 20.8 & 100 & 0.00 & .140 \\
\hline Head of bed (HOB) elevation more than 20 (40) degrees & 75 & 25 & 100 & 0.00 & .064 \\
\hline HOB elevation 40 degrees & 83.3 & 16.7 & 100 & 0.00 & .140 \\
\hline Administering DVT prophylaxis & 50 & 50 & 100 & 0.00 & $.005 *$ \\
\hline Administering PUD prophylaxis & 75 & 25 & 100 & 0.00 & .064 \\
\hline $\begin{array}{l}\text { Daily Sedation Vacation \& Daily Assessment of the } \\
\text { Readiness to Wean }\end{array}$ & 62.5 & 37.5 & 70.85 & 29.15 & 682 \\
\hline Sedation vacation at night & 66.7 & 33.3 & 75 & 25 & .653 \\
\hline Starting sedation at morning & 58.3 & 41.7 & 66.7 & 33.3 & .673 \\
\hline \multicolumn{6}{|l|}{ Mouth Care with Chlorhexidine } \\
\hline Utilizing Chlorhexidine for oral care & 50 & 50 & 100 & 0.00 & $.046^{*}$ \\
\hline Providing oral care /8 hours & 66.7 & 33.3 & 75 & 25 & .653 \\
\hline Suctioning the subglottic region & 75 & 25 & 100 & 0.00 & .064 \\
\hline Utilizing clean gloving for oral suction & 100 & 0.00 & 100 & 0.00 & I \\
\hline
\end{tabular}

${ }^{*} p$ is significant if $\leqslant .05$

Table 4. The knowledge related to the VAP prevention bundle of nurses before and after training

\begin{tabular}{|c|c|c|c|c|c|}
\hline \multirow{2}{*}{ Practice } & \multicolumn{2}{|c|}{ Before the training $(n=12)$} & \multicolumn{2}{|c|}{ After the training $(n=12)$} & \multirow{2}{*}{$p$-value } \\
\hline & Compliant (\%) & Noncompliant (\%) & Compliant (\%) & Noncompliant (\%) & \\
\hline Head Elevation 30-45 degrees & 25.00 & 75.00 & 91.70 & 8.30 & $.000 *$ \\
\hline Administration of DVT prophylaxis & 72.74 & 27.26 & 100.00 & 0.00 & $.008^{*}$ \\
\hline Administration of PUD prophylaxis & 79.54 & 20.46 & 100.00 & 0.00 & $.024 *$ \\
\hline Daily Sedation Vacation & 12.89 & 87.11 & 100.00 & 0.00 & $.000 *$ \\
\hline Daily Assessment of the Readiness to Wean & 22.25 & 77.75 & 100.00 & 0.00 & $.000^{*}$ \\
\hline $\begin{array}{l}\text { Daily Spontaneous Breathing Trials, if } \\
\text { patient is ready to wean }\end{array}$ & 3.54 & 96.46 & 68.97 & 31.03 & $.000^{*}$ \\
\hline Mouth Care with Chlorhexidine & 63.01 & 36.99 & 95.84 & 4.16 & $.019 *$ \\
\hline
\end{tabular}

${ }^{*} p$ is significant if $\leqslant .05$

Table 6 shows the medical, surgical history and the current diagnosis of the patients participating in the study before and after the training program. Before the training program, 20\% of the patients had no past medical history while after the training program the past medical history was almost twofold higher (39.3\%).Two third of patients treated before and after the training $(66.7 \%$ and $64.30 \%$, respectively) had no past surgical history.

Table 7 shows the relationship between age, length of intubation, \& date of positive VAP manifestations and the incidence of VAP in patients admitted to the ICU before the training and those admitted after the training.

These result showed that this study has great implications for the practice of nursing. Ventilator acquired pneumonia is a preventable nosocomial infection. Nurses can contribute greatly to a decrease in VAP rate in their individual critical care units after the implementation of VAP Prevention Published by Sciedu Press
Bundle. In essence, nursing can own their units' ventilator acquired pneumonia rate. As Nightingale believed, nurses are responsible for keeping themselves, their patients and their surroundings clean and free from disease.

By educating nurses and providing them with opportunities to demonstrate competency in their care, opportunities to enhance patient outcomes increase. By teaching nurses how to comply with IHI VAP Prevention Bundles, VAP rates will decrease. This is especially true for nurses who are new to the critical care environment. Orientation of these nurses needs to include VAP Prevention Bundle and a chance for the nurses to work with the equipment and patients prior to being on the unit because VAP bundles is not typically taught during nursing education. In addition, the effect of implementing these guidelines on patients' outcomes, including VAP incidence in critical care units (CCUs), should be monitored. 
Table 5. Distribution of the studied patients according to their past medical/surgical history and current diagnosis

\begin{tabular}{|c|c|c|c|c|c|}
\hline \multirow{2}{*}{ Variables } & \multicolumn{2}{|c|}{ Before nurses' training } & \multicolumn{2}{|c|}{ After nurses' training } & \multirow{2}{*}{$p$-value } \\
\hline & $n=15$ & $\%$ & $n=28$ & $\%$ & \\
\hline \multicolumn{6}{|l|}{ Age/year } \\
\hline$<20$ & 0 & 0.00 & 2 & 7.14 & \multirow{8}{*}{$\begin{array}{l}p \text { value of } \\
\chi^{2} \text { test }=0.148\end{array}$} \\
\hline $20-35$ & 1 & 6.67 & 6 & 21.43 & \\
\hline $36-50$ & 1 & 6.67 & 4 & 14.29 & \\
\hline $51-65$ & 4 & 26.67 & 4 & 14.29 & \\
\hline $66-80$ & 6 & 40.00 & 4 & 14.29 & \\
\hline$>80$ & 3 & 20.00 & 8 & 28.57 & \\
\hline Min-Max & \multicolumn{2}{|l|}{$26-87$} & \multicolumn{2}{|l|}{$15-90$} & \\
\hline Mean \pm SD & \multicolumn{2}{|c|}{$67.07 \pm 16.53$} & \multicolumn{2}{|c|}{$56.21 \pm 25.74$} & \\
\hline \multicolumn{6}{|l|}{ Sex } \\
\hline Male & 8 & 53.33 & 20 & 71.43 & \multirow{2}{*}{$\begin{array}{l}p \text { value of } \\
\chi^{2} \text { test }=0.235\end{array}$} \\
\hline Female & 7 & 46.67 & 8 & 28.57 & \\
\hline \multicolumn{6}{|c|}{ Length of intubation and ventilation (days) } \\
\hline Min-Max & \multicolumn{2}{|l|}{$4-14$} & \multicolumn{2}{|c|}{$3-15$} & \multirow{2}{*}{$\begin{array}{l}p \text { value of } \\
T \text {-test }=0.392\end{array}$} \\
\hline Mean \pm SD & \multicolumn{2}{|c|}{$7.87 \pm 3.16$} & \multicolumn{2}{|c|}{$6.79 \pm 4.25$} & \\
\hline \multicolumn{6}{|c|}{ Length of stay in ICU (days) } \\
\hline Min-Max & \multicolumn{2}{|l|}{$6-15$} & \multicolumn{2}{|l|}{$2-20$} & \multirow{2}{*}{$\begin{array}{l}p \text { value of } \\
T \text {-test }=0.556\end{array}$} \\
\hline Mean \pm SD & \multicolumn{2}{|c|}{$9.40 \pm 2.92$} & \multicolumn{2}{|c|}{$8.79 \pm 5.08$} & \\
\hline
\end{tabular}

Table 6. Distribution of the studied patients according to their past medical/surgical history and current diagnosis

\begin{tabular}{|c|c|c|c|c|}
\hline \multirow{2}{*}{ Variables } & \multicolumn{2}{|c|}{ Before nurses' training } & \multicolumn{2}{|c|}{ After nurses' training } \\
\hline & $n=15$ & $\%$ & $n=28$ & $\%$ \\
\hline \multicolumn{5}{|l|}{ Past medical history } \\
\hline None & 3 & 20.00 & 11 & 39.30 \\
\hline Hypertension & 5 & 33.30 & 10 & 35.70 \\
\hline Coronary artery disease & 3 & 20.00 & 8 & 28.60 \\
\hline Chronic kidney disease & 1 & 6.70 & 2 & 7.10 \\
\hline Chronic lung disease & 3 & 20.00 & 6 & 21.40 \\
\hline Neuromuscular disease & 4 & 26.70 & 4 & 14.30 \\
\hline \multicolumn{5}{|l|}{ Past surgical history } \\
\hline None & 10 & 66.70 & 18 & 64.30 \\
\hline Neurosurgery & 1 & 6.70 & 0 & 0.00 \\
\hline Orthopedic surgery & 3 & 20.00 & 4 & 14.30 \\
\hline Abdominal surgery & 1 & 6.70 & 5 & 17.90 \\
\hline \multicolumn{5}{|l|}{ Patient current diagnosis } \\
\hline Pulmonary Disorder & 6 & 40.00 & 9 & 32.10 \\
\hline Renal Disorder & 1 & 6.70 & 3 & 10.70 \\
\hline Neurologic Disorder & 6 & 40.00 & 8 & 28.60 \\
\hline Trauma & 1 & 6.70 & 7 & 25.00 \\
\hline Infection & 2 & 13.30 & 0 & 0.00 \\
\hline Cardiac Disorder & 0 & 0.00 & 7 & 25.00 \\
\hline
\end{tabular}


Table 7. Incidence of VAP in both study groups, patients admitted to the ICU before conducting the training versus those admitted to the ICU after the training

\begin{tabular}{|c|c|c|c|c|c|c|c|c|c|}
\hline \multirow{3}{*}{ Incidence of VAP } & \multicolumn{4}{|c|}{ Before nurses' training $(n=15)$} & \multicolumn{4}{|c|}{ After nurses' training $(n=28)$} & \multirow{3}{*}{$p$-value } \\
\hline & \multicolumn{2}{|l|}{ Yes } & \multicolumn{2}{|c|}{ No } & \multicolumn{2}{|c|}{ Yes } & \multicolumn{2}{|c|}{ No } & \\
\hline & $\mathbf{n}$ & $\%$ & $\mathbf{n}$ & $\%$ & $\mathbf{n}$ & $\%$ & $\mathbf{n}$ & $\%$ & \\
\hline VAP & 10 & 66.7 & 5 & 33.3 & 6 & 21.4 & 22 & 78.6 & $* .003$ \\
\hline
\end{tabular}

$* p$ value of $\chi^{2}$ test (Chi-square test) is significant if $\leq .05$

\section{Discussion}

This study has great implications for the practice of nursing. Ventilator acquired pneumonia is a preventable nosocomial infection. Nurses can contribute greatly to a decrease in VAP rate in their individual critical care units. In essence, nursing can own their units' ventilator acquired pneumonia rate. As Nightingale believed, nurses are responsible for keeping themselves, their patients and their surroundings clean and free from disease.

By educating nurses and providing them with opportunities to demonstrate competency in their care, opportunities to enhance patient outcomes increase. By teaching nurses how to comply with IHI VAP Prevention Bundles, VAP rates will decrease. This is especially true for nurses who are new to the critical care environment. Orientation of these nurses needs to include VAP Prevention Bundle and a chance for the nurses to work with the equipment and patients prior to being on the unit because VAP bundles is not typically taught during nursing education. In addition, the effect of implementing these guidelines on patients' outcomes, including VAP incidence in critical care units (CCUs), should be monitored.

Concerning nurse's knowledge related to VAP, its definition, diagnosis, and complications of MV; it was found that less than half of the nurses knew the definition of VAP before the training program. The training program was effective in increasing nurses' knowledge related to the definition of VAP to be that all nurses were knowledgeable about the definition of VAP.

Concerning the risk factor of wearing clean gloves during tracheal suctioning, it was found that only half of the nurses knew that it is necessary to utilize a sterile glove for tracheal suctioning. This might be due to the lack of nurses' knowledge regarding the safe and effective suctioning technique

With respect to nurses' knowledge related to VAP Prevention Bundle, the study revealed that one fourth of the nurses had a wrong believe that the HOB elevation at twenty degree is recommended to prevent VAP. After the training program, all nurses knew that the recommended angle for head elevation to prevent VAP is at least forty degrees.

Published by Sciedu Press
With respect to nurses' knowledge regarding DVT prophylaxis, it was found that only half of nurses knew that DVT prophylaxis is recommended and is one of the elements of VAP Prevention Bundle. Whereas after the training, all nurses knew that the implementation of DVT prophylaxis regimen is a basic part in VAP prevention bundle.

Nurses' knowledge regarding PUD prophylaxis was also improved post training, as all nurses knew that this item is vitally recommended to prevent VAP

Before the training session, the recommendation of mouth care with chlorhexidine was known by only half of the nurses but after the training program, all the nurses knew the importance of mouth care in preventing the incidence of VAP.

Concerning nurses' compliance to VAP Prevention Bundle practices before and after the training, it was found that a significant improvement in the compliance of nurses to all five elements of the bundle was found.

In conclusion, education alone is not enough to reduce the incidence of VAP. Providing bundle care without educating the nurses on appropriate use cannot reduce the incidence of VAP. By using both education and improving nurses skill, the incidence of VAP will reduce. Findings indicated that when nursing interventions of IHI Bundle care are properly applied by nurses, the risk of developing a VAP can be decreased and the time period before developing a VAP can be increased.

\section{Limitations of the study}

No study is without limitations and this study is not an exception. The first limitation of this study is in its allocated duration, as it does not allow the evaluation of the educational intervention on the long-term, and whether practices will remain adequate few months after the training.

Also, this study did not take into consideration all the factors that may be determining of the occurrence of VAP, such as the nurses/patients ratio, the shortage of nurses or the overload, which sometimes forces the nurses to act in a manner against the procedure. Including all the factors would have required a much higher level of effort than possible for this study. 


\section{Conclusion}

The concept of a ventilator care bundle continues to be the focus of many international policies, initiatives on patient safety, and is one of the six stated safety aims. This study acknowledges that although we cannot change the patient's age, gender race or preexisting comorbidities and/or chronic disease conditions, we can reduce the hospital-acquired risk of developing a VAP by incorporating the optimal nursing bundle as a routine component of care in the ventilator patient. Moreover, VAP can be then be considered a nursing-sensitive indicator that reflects patient outcomes.

This study demonstrated nurses' knowledge and skills regarding VAP prevention bundle were improved after the training program. Additionally, the training program on VAP prevention bundle directed to nurses in CCUs dramatically decreased the incidence of VAP.

\section{RECOMMENDATIONS}

The recommendations of the current study can be classified as recommendations related to practical, educational, administrative, or researches recommendations.

Practical recommendations: Implementing evidence-based practices related to VAP Prevention Bundle into $\mathrm{CCU}$ prac- tices.

Educational recommendations: Providing in-service trainings to the for critical care nurses about VAP Prevention Bundle.

Administrative recommendations: Developing policies and guidelines adapted from the international evidence based guidelines for VAP prevention. Developing tools of documentation facilitating the implementation of evidence based practices; particularly VAP prevention bundle.

Research related recommendations: Further studies are recommended to be conducted in the future including researches

- Assessing the impact of educational interventions regarding VAP prevention on patients' outcomes, such as; duration of hospital stay, and cost of treatment and hospitalization.

- Assessing the impact of similar educational interventions over a long period of time (more than 3 months).

- Assessing the impact of nurses' overload on VAP incidence rate.

\section{CONFLICTS OF INTEREST DISCLOSURE}

The authors declare that there is no conflict of interest.

\section{REFERENCES}

[1] Ryland R. Ventilation, Mechanical, Medscape. 2010. Available from: http://emedicine.medscape.com/article/304068-o verview

[2] Rello J. A European care bundle for management of ventilatorassociated pneumonia. Journal of Critical Care. 2011; 26: $3-$ 10. PMid:20537504 http://dx.doi.org/10.1016/j.jcrc. 20 10.04 .001

[3] Apostolopoulou E, Bakakos P, Katostaras T, et al. Incidence and Risk factors for ventilator-associated pneumonia in 4 multidisciplinary intensive care units in Athens, Greece. Respiratory Care. 2003; 48(7): 681-6. PMid:12841859

[4] Center for Disease Control and Prevention. Ventilator-Associated Pneumonia (VAP) Event. 2012.

[5] Pierson D. Intensive mechanical ventilation. In Albert R, Sbpiro S, Jett J. Clinical respiratory medicine. 2nd London: Saunders; 2004. 189-209.
[6] Institute for Healthcare and Improvement. Getting Started Kit: prevention of ventilator-associated pneumonia in adults and children how-to guide. 2009. Available from: http: //www . saferhealthcarenow.ca/EN/Interventions/V AP/Documents/VAP\%20Getting\%20Started\%20Kit.pdf

[7] Koenig S, Truwit J. Ventilator-associated pneumonia: diagnosis, treatment, and prevention. Clinical Microbiology Review. 2006; 19 (4): 637-57. PMid:17041138 http://dx.doi.org/10.1128/CMR $.00051-05$

[8] Guidelines for the prevention of ventilator-associated pneumonia in adults in Ireland, A Strategy for the Control of Antimicrobial Resistance in Ireland. 2011. Available from: http://www.hpsc.i e/hpsc/AZ/MicrobiologyAntimicrobialResistance/Infe ctionControlandHAI/Guidelines/File, 12530, en.pdf

[9] Tolentino A, Ruppert S, Shiao S. Evidence-based practice: use of the ventilator bundle to prevent ventilator-associated pneumonia. American Journal of Critical Care. 2007; 16(1): 20-7. 